\title{
Pt Loaded Alumina Ceramic Catalysts for Micro Thermoelectric Hydrogen Sensors
}

\author{
Kazuki TAJIMA, Woosuck SHIN, Maiko NISHIBORI, Toshio ITOH, Noriya IZU and Ichiro MATSUBARA \\ Advanced Manufacturing Research Institute, AIST, 2266-98, Anagahora, Shimo-Shidami, Moriyama-ku, Nagoya-shi 463-8560
}

\author{
白金担持アルミナセラミック触媒を用いたマイクロ熱電式水素センサー \\ 田嶌一樹 ·申ウソク · 西堀麻衣子 · 伊藤敏雄 ·伊豆典哉 ·松原一郎 \\ 産業技術総合研究所， 463-8560 名古屋市守山区大字下志段味字穴ヶ洞 2266-98
}

\begin{abstract}
The micro-thermoelectric hydrogen sensor (micro-THS) detects the hydrogen gas working with the thermoelectric effect of SiGe thin film and the Pt-catalyzed exothermic reaction of hydrogen oxidation. Integration of Pt/ alumina ceramic catalyst on the membrane of the micro-THS was evitable to ensure the high sensitivity and longterm stability of the sensor. The various compositions of Pt/alumina ceramic catalysts were milled by a ball-mill technique to improve the dispersion of the catalyst, and were mixed with conventional organic vehicle like paste. The paste was deposited on micro-THS using dispenser method and the effects of the ball-mill technique and catalyst composition on the sensitivity, $\Delta V_{s}$, of the micro-THS for the hydrogen/air mixture gas flow were investigated. The shape of ceramic catalyst became uniform, and agglomeration of catalyst powder could not be observed using ball-mill technique. The 10 mass $\% \mathbf{P t}$ /alumina ceramic catalyst was the optimized platinum content of the ball-milled powder paste, and the micro-THS with this catalyst produced the larger voltage signal of 12.2 $\mathrm{mV}$ at the operating temperature of $100^{\circ} \mathrm{C}$.

[Received March 13, 2006; Accepted May 18, 2006]
\end{abstract}

Key-words : Integration, Ceramic catalyst, Ball-mill, Membrane, Hydrogen sensor, Thermoelectric, Microfabrication

1. Introduction

Hydrogen gas is the most attractive and ultimate candidate for a future fuel and an energy carrier because it burns cleanly. The common requirement in this infra technology area is the ability to detect and monitor hydrogen gases, however, hydrogen gas sensors that can quickly and reliably detect hydrogen gas over a wide range of oxygen and moisture concentrations are not currently available. Traditional inflammable gas sensors are of the semiconductor oxide type or hot-wire type, where the resistance of sensor materials changes markedly as sensor surface area decreases or as the temperature of sensor materials increases, respectively. These sensors need to be heated around $400^{\circ} \mathrm{C}$ in order to keep proper operation, and principally have poor selectivity to hydrogen gas because it responses to other combustible gases, such as methane and carbon monoxide. ${ }^{1)}$ Recently, there are other representative hydrogen sensors with different operating principles, such as palladium-gated field-effect transistor type, ${ }^{2)}$ optical fiber type $^{3)}$ or piezoelectric type. ${ }^{4)}$ All the sensors listed above normally respond to very low concentration of hydrogen, however, their signals saturate over about $1 \%$ hydrogen in air.

Recently, we have focused microfabrication technique with novel deposition and etching processing which is used for integrated circuit fabrication to apply for preparation of micro-thermoelectric hydrogen sensor (micro-THS) using silicon substrate. ${ }^{5), 6)}$ This sensor with a new-type sensor principle taking advantage of both the thermoelectric effect and selective catalytic reaction of platinum catalyst with hydrogen has been shown to exhibit a hydrogen-selective sensor performance without problem of drift. ${ }^{7)-9)}$ Platinum thin film was used as a catalyst layer, and SiGe thin film was used as a thermoelectric layer, which generates thermoelectric voltage by the local temperature differential induced by hydrogen-oxidation heat. In the viewpoint of amplification of the temperature difference by catalyst reaction of heat, the major sensor patterns of thermoelectric layer, heater pattern and catalyst was built on a thin dielectric membrane so that the temperature difference across the thermoelectric layer was optimized due to a lower thermal conductivity compared to the silicon substrate. Especially, integration of catalyst on membrane is one of a most important technique for high sensitivity of the sensor.

In our previous work, we have fabricated the micro-THS with 40 mass $\% \mathrm{Pt}$ loaded alumina ( $\mathrm{Pt} /$ alumina) ceramic catalyst deposited to increase the effective surface area of the catalyst. ${ }^{10), 11)}$ With this new ceramic catalyst, we have succeeded to enhance the sensitivity of the sensor expecting longterm stability, and the micro-THS with $\mathrm{Pt} /$ alumina ceramic catalyst at the operating temperature of $100^{\circ} \mathrm{C}$ only showed the high catalytic activity for hydrogen and the high hydrogen selectivity was achieved, as other inflammable gases interferences on hydrogen were less than $5 \%$. However, the platinum dispersion in nanoscale was rather poor, which may effect on the long-term stability of the sensor.

In this study, we have focused on fabricating a ceramic catalyst with a good dispersion of platinum nanoparticle using a ball-mill technique, expecting the improved sensing property of micro-THS with this new ceramic catalyst. We have also investigated the optimum platinum metal content in the catalyst.

\section{Experimental}

The micro-THS with Pt/alumina ceramic catalyst was fabricated by the following equipment. The double-side polished $\mathrm{Si}$ wafer ((100) p-type, Shinetsu Inc.) of $0.35 \mathrm{~mm}$ thickness was used as a substrate. The wafer was thermally oxidized to form an insulating $\mathrm{SiO}_{2}$ layer and then nitride film was deposited by low-pressure chemical vapor deposition (LPCVD) to form $250 \mathrm{~nm} \mathrm{Si}_{3} \mathrm{~N}_{4} / 80 \mathrm{~nm} \mathrm{SiO}{ }_{2}$ multi layers on both the front and back surfaces.

A sintered target of 1 at $\%$ boron-doped $\mathrm{Si}_{0.8} \mathrm{Ge}_{0.2}$ (p-type, Toshima Manufacturing Co., Ltd.) with a purity of $99.997 \%$ was used for the helicon sputtering deposition of SiGe thermoelectric thin film. ${ }^{12)}$ The substrate temperature was $200^{\circ} \mathrm{C}$ and the working pressure was $1.7 \times 10^{-1} \mathrm{~Pa}$ with the argon 

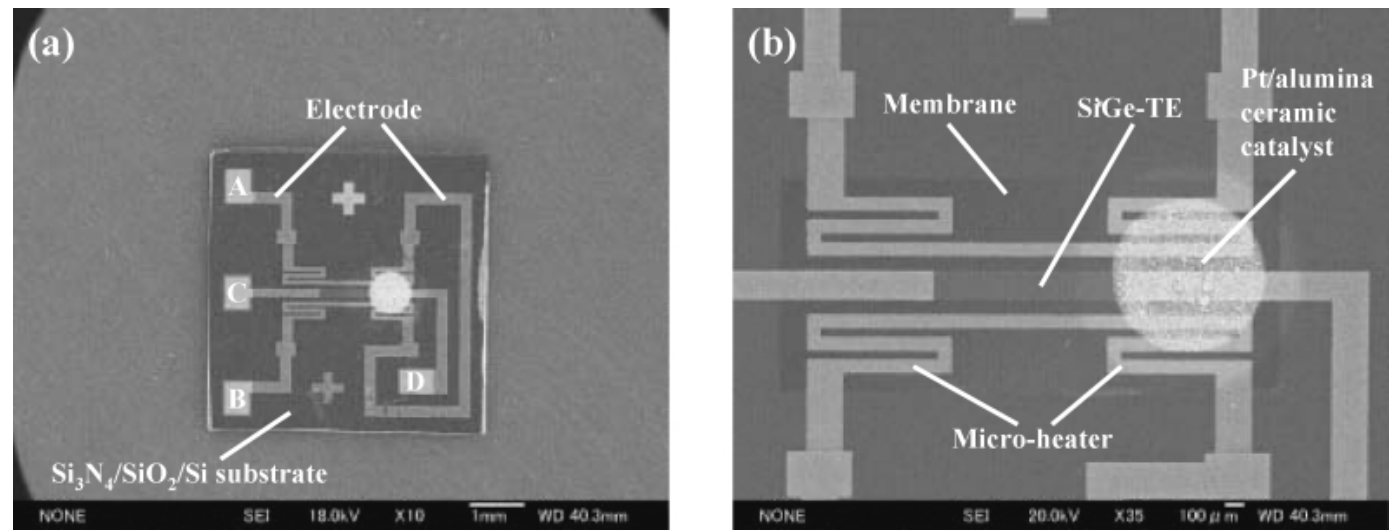

Fig. 1. FE-SEM images of micro-thermoelectric hydrogen sensor on Si wafer with micro-heater on single membrane. (a) is entire device image and (b) is integrated patterns on membrane.

flow rate of $20 \mathrm{cc} / \mathrm{min}$. After the deposition, the SiGe thermoelectric pattern was fabricated by reactive ion etching (RIE) method, and thermal annealing at $1000^{\circ} \mathrm{C}$ was carried out for $5 \mathrm{~h}$ to crystallize the SiGe thermoelectric thin film. The thermoelectric film was covered by a passivation layer of $\mathrm{SiO}_{2}$ using plasma-enhanced chemical vapor deposition (PECVD).

The micro-heater and electrode lines were fabricated by the lift off technique using the adhesion layer of $30 \mathrm{~nm}$ titanium followed by $150 \mathrm{~nm}$ platinum or gold. The surface of device was covered by a passivation layer of $\mathrm{SiO}_{2}$. Next, wet-etching windows were fabricated on the reverse side of the substrate with the lithography pattern transfer and RIE etching of nitride layers. Using these nitride windows as etching masks, wet etching using aqueous $\mathrm{KOH}$ solution was performed in membrane structures with thickness of about $300 \mathrm{~nm}$.

The catalyst was prepared on the one side of membrane by dispenser method using ceramic catalyst of platinum metal dispersed alumina, Pt/alumina ceramic catalyst. ${ }^{10), 13)}$ Figure 1 shows the FE-SEM images of the micro-THS with Pt/alumina ceramic catalyst. The substrate size with single membrane structure was $5 \times 5 \mathrm{~mm}^{2}$ in Fig. 1 (a). Figure 1 (b) is a close up of the membrane structure in Fig. 1(a). The backside of silicon substrate was etched away to fabricate the membrane structure. The area of $\mathrm{Pt} /$ alumina ceramic catalyst on the membrane was $0.64 \mathrm{~mm}^{2}$, and membrane could be effectively heated using a micro-heater as shown in Fig. 1(b). The heater electrodes were A and B in Fig. 1(a). The change of voltage signal by the thermoelectric effect of SiGe thin film for the heat of hydrogen-oxidized reaction at the $\mathrm{Pt}$ /alumina ceramic catalysts side was detected using voltage electrodes of C and D in Fig. 1(a).

The Pt/alumina ceramic catalyst layer was deposited with viscous paste, which was a mixture of the alumina powder and conventional organic vehicle. The ceramic catalyst powder was platinum metal deposited alumina powder. The platinum metal was deposited on alumina by impregnation using metal chloride of platinum (Hydorogen hexachloroplatinate(IV), Inuisho Precious Metals Co., Ltd.) and alpha-alumina (Taimicron, Taimei Chemicals Co., Ltd.). We have changed the content of platinum metal in the $\mathrm{Pt} /$ alumina ceramic catalysts, such as 5, 10, 20 and 40 mass $\%$. The alumina powder was dispersed in aqueous solution of metal chloride of platinum, and then dried to be powder again at $300^{\circ} \mathrm{C}$ for $2 \mathrm{~h}$. After drying, the catalyst powder was milled by a ball-mill (Retsch, MM200) to enhance the dispersion in this study. Then, the ceramic catalyst of a viscous paste was deposited with the diameter of around $0.8 \mathrm{~mm}$ by dispenser method on the one side of membrane, and was annealed at $300^{\circ} \mathrm{C}$ for $2 \mathrm{~h}$ to vaporize chlorine and organic vehicle in the paste. This dispenser method has some advantage such as no Photo-mask is necessary and easy combination of materials is possible.

The material characterization of the $\mathrm{Pt} /$ alumina ceramic catalyst was carried out using an X-ray diffractometer with $\mathrm{Cu} \mathrm{K} \alpha$ (XRD; Rigaku, RINT2100), optical microscope (HISCOPE Advanced; HiROX, KH-3000VD) and a transmission electron microscope (TEM; JEOL, JEM-2010).

A gas flowing system with a test chamber, IR camera, and data system was used to evaluate the hydrogen sensing properties of the micro-THS. The IR camera is for the in-situ monitoring of the surface temperature of the micro-THS evaluating the combustion performance of the catalyst on the membrane. The data of temperature and voltage signal of the micro-THS as well as the gas flow were all automatically processed or controlled by a computer. The flow of the mixture gas of hydrogen and dry air and the dry air were alternately switched through the measurement chamber with flow rate of $200 \mathrm{cc} / \mathrm{min}$, and the performance of combustor and sensor were investigated changing the temperature of membrane from 25 to $120^{\circ} \mathrm{C}$ using micro-heater control.

\section{Results and discussion}

\subsection{Characterization of $\mathrm{Pt} /$ alumina ceramic catalyst}

Figure 2 shows the XRD patterns of the Pt/alumina ceramic powder (a) as-deposited and (b) after annealing. The platinum chlorides in all powders were changed into the platinum metal after annealing. The diffraction peaks corresponding to the (111) and (200) planes with $2 \theta$ of platinum metal were located at $39.8^{\circ}$ and $46.2^{\circ}$ in Fig. 2(b), respectively. The grain size of platinum metal in catalyst was estimated using the Williamson-Hall equation: ${ }^{14}$

$$
\beta \cdot \cos \theta=K \cdot \lambda / D_{\mathrm{XRD}}+2 \eta \sin \theta
$$

where $\beta$ is the full width at half maximum (FWHM) of the respective peak, $\theta$ is the angle of diffraction, $K$ is a constant, $\lambda$ is the $\mathrm{X}$-ray wavelength, $D_{\mathrm{XRD}}$ is the grain size, and $\eta$ is the lattice strain. Using this equation, the grain sizes of platinum metals in catalysts with $40,20,10$ and 5 mass \% platinum after annealed were estimated to be $14,12,10$ and $9 \mathrm{~nm}$, respectively.

Figure 3 shows the optical micrographs of 40 mass $\% \mathrm{Pt} /$ alumina ceramic catalysts after annealing on the micro-THS. The starting catalyst powder of Fig. 3(a) was prepared using 

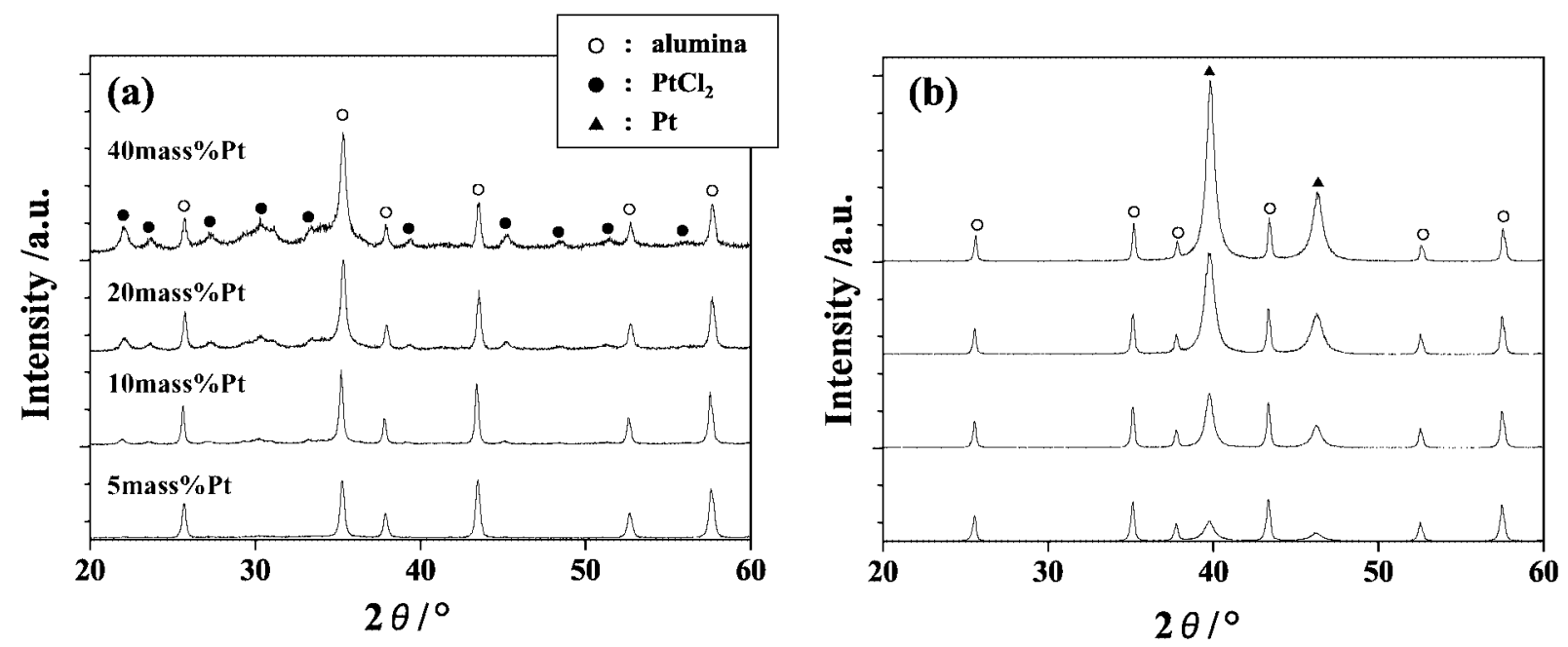

Fig. 2. XRD patterns of Pt/alumina powders (a) before annealing and (b) after annealing.
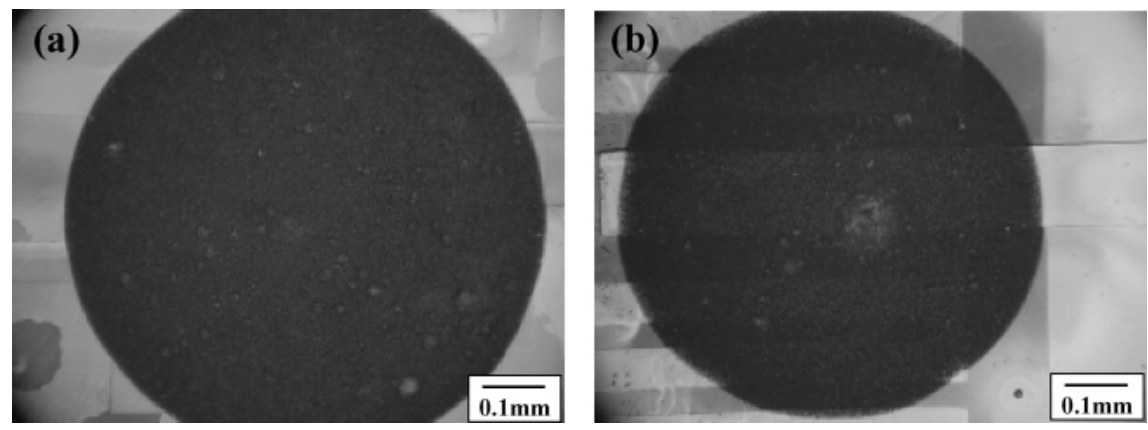

Fig. 3. Optical microscope images of 40 mass $\%$ Pt loaded alumina ceramic catalysts after annealing. The starting catalyst powder of (a) was prepared using ball-mill technique, and (b) was not prepared using ball-mill technique.

ball-mill technique, and that of Fig. 3(b) was not prepared using ball-mill technique. The diameters of ceramic catalyst for all micro-THS were controlled to be same about $0.8 \mathrm{~mm}$. When the 40 mass\% Pt/alumina ceramic catalyst was not prepared using the ball-mill technique, the ceramic catalyst became thin layer and then the device pattern underneath the catalyst with large segregation of catalyst powder with the size of $0.1 \mathrm{~mm}$ could be observed in Fig. 3(b). The deviation of thickness of the catalyst of Fig. 3(b) was very large, and the difference of thickness of thick and thin points of catalyst layer was larger than $10 \mu \mathrm{m}$. On the other hand, the catalyst of Fig. 3 (a) was precise, large segregation of catalyst powder could not be observed. These results show that the dispersion of catalyst was improved using ball-mill technique, resulting in good application of the catalyst paste.

Figure 4 shows the microstructure of (a) 40 and (b) 10 mass \% Pt/alumina ceramic catalysts in nanometer scale. The grain sizes of alumina for all samples were observed to be same about $100 \mathrm{~nm}$. The platinum metal grains shown as black spots, were on the surface of alumina particle. The average grain sizes of the platinum metals of 40 and 10 mass $\%$ $\mathrm{Pt} /$ alumina ceramic catalysts evaluated this TEM observation were about $12 \mathrm{~nm}$ and $9 \mathrm{~nm}$, respectively. This result of average platinum sizes is consistent with that of the XRD measurement, which estimated to be 14 and $10 \mathrm{~nm}$ using the Williamson-Hall equation, respectively. Though there are many agglomeration in the catalyst of 40 mass $\% \mathrm{Pt} /$ alumina, the dispersion of platinum in the catalyst of 10 mass $\%$ looks fairly good. This is a great difference from the results of previous work of ours, when we could not control the agglomeration of platinum in 10 mass $\% \mathrm{Pt} /$ alumina. ${ }^{10)} \mathrm{We}$ concluded that the ball-mill technique was effective to disperse the catalyst with a low content of platinum metal.

\subsection{Sensing property of the micro-THS with Pt/alumina} ceramic catalyst

Figure 5 shows IR images of the micro-THS with 10 mass $\%$ $\mathrm{Pt} /$ alumina ceramic catalyst, this starting catalyst powder was prepared using ball-mill technique, at operating temperature of $100^{\circ} \mathrm{C}$ tested by switching the $1 \%$ hydrogen and air gas alternately. We chose the catalyst surface temperature as the operating temperature. At membrane of the micro-THS, one side of membrane is the hot side covered with ceramic catalyst, point $\mathrm{A}$, and the other is the cold side, point $\mathrm{B}$, where the micro-heater meander and electrode are shown. The temperature at the two voltage leads, $T_{\mathrm{A}}$ and $T_{\mathrm{B}}$, increased monotonically when hydrogen gas flows into the test chamber. When the temperature of point $\mathrm{A}$ was changed from 100.2 to $140.7^{\circ} \mathrm{C}$, before (Fig. 5(a)) and after (Fig. 5(b)) the $1 \%$ hydrogen gas flow in air, with the Pt-catalyzed exothermic reaction of hydrogen oxidation, at operating temperature of $100^{\circ} \mathrm{C}$, the catalytic activity $\left(\Delta T_{\mathrm{A}}\right)$ of the catalyst on the micro-THS was $40.3^{\circ} \mathrm{C}$. However, the temperature of point $\mathrm{B}$ hardly changed because of the good thermal insulating structure of the micro-THS. The temperature difference $\Delta T_{\mathrm{A}-\mathrm{B}}$ saturated much faster at a certain level than $\Delta T_{\mathrm{A}}$ or $\Delta T_{\mathrm{B}}$, resulting in a flat $\Delta T_{\mathrm{A}-\mathrm{B}}$ response. ${ }^{5)}$ This is the important rea- 
(a)

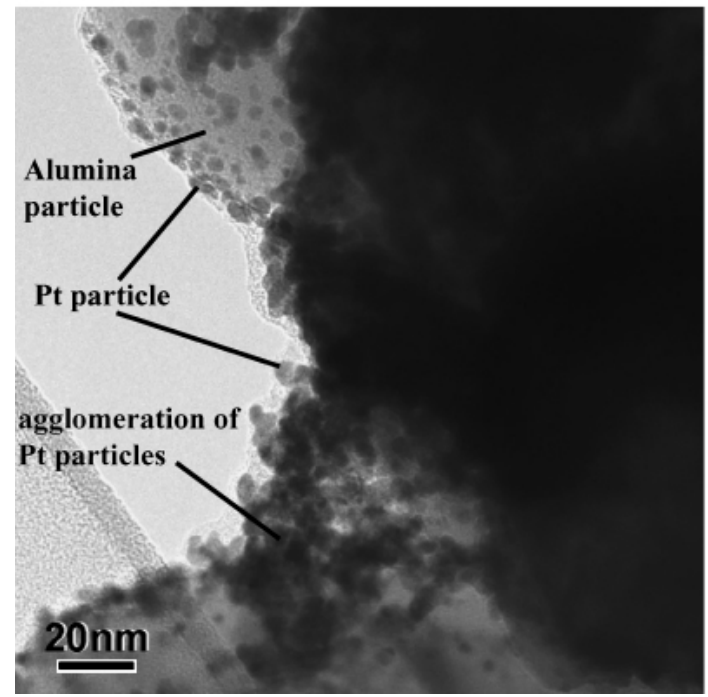

(b)

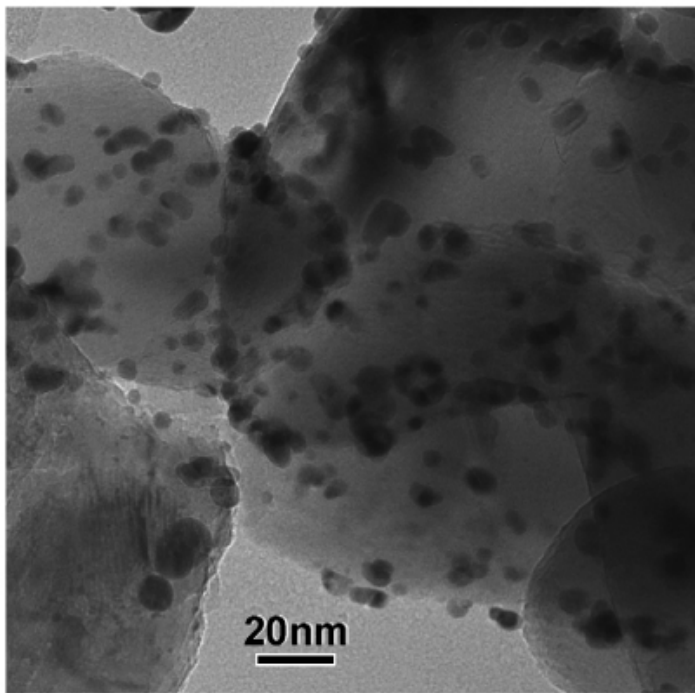

Fig. 4. TEM images of (a) 40 and (b) 10 mass $\% \mathrm{Pt} /$ alumina ceramic catalysts using ball-mill technique.

(a)

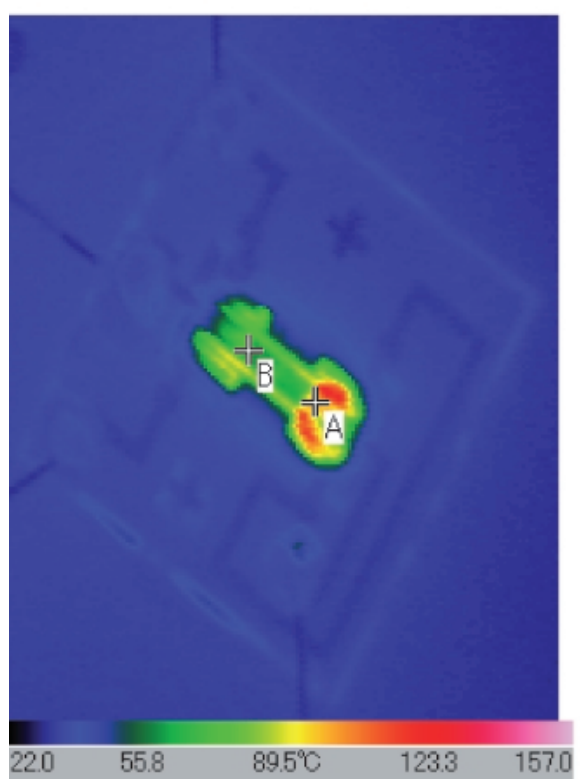

(b)
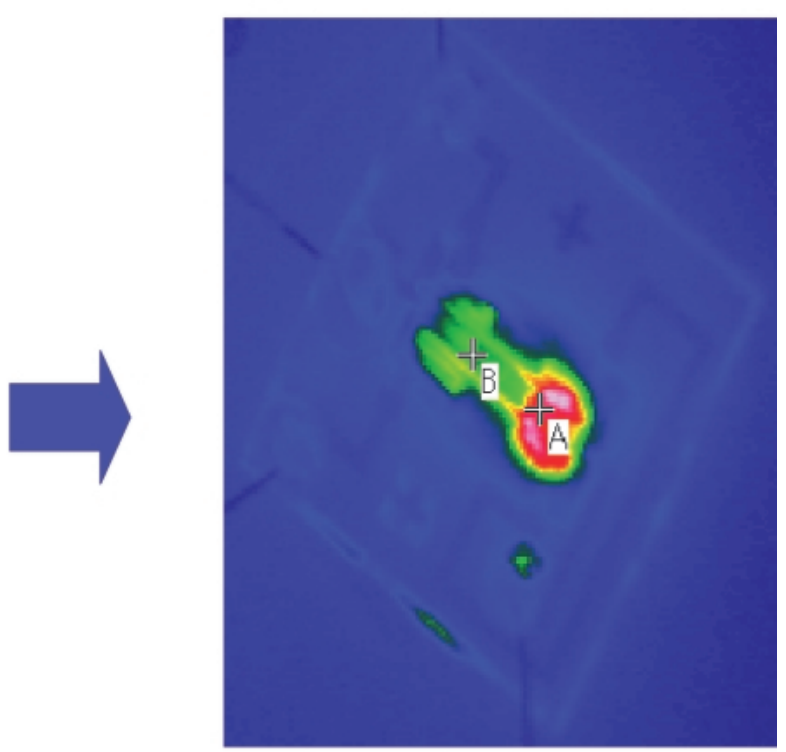

Fig. 5. IR images of micro-thermoelectric hydrogen sensors with 10 mass $\% \mathrm{Pt} /$ alumina ceramic catalyst, the starting catalyst powder was prepared using ball-mill technique, at operating temperature of $100^{\circ} \mathrm{C}$. (a) is only air was flowing and (b) is $1 \%$ hydrogen gas in air was flowing.

son why both hot and cold sides should be on the membrane in order to minimize offset voltage at same temperature.

Figure 6 shows the hydrogen sensing properties of the micro-THS with 40 mass $\% \mathrm{Pt} /$ alumina ceramic catalyst at various operating temperatures for $1 \%$ hydrogen in air. The starting catalyst powder of Fig. 6(a) was prepared using ballmill technique, and that of Fig. 6(b) was prepared using old method without ball-mill technique. In Fig. $6(\mathrm{a}), \Delta V_{\mathrm{S}}$ values saturated over the elapsed time of $100 \mathrm{~s}$ with the progress of the hydrogen-oxidized reaction. The saturated values of $\Delta V_{\mathrm{S}}$ for the hydrogen response of the micro-THS with $\mathrm{Pt} /$ alumina ceramic catalyst about $300 \mathrm{~s}$. When the operating temperature was changed the temperature increase at catalyst side varied from 22.34 to $49.82^{\circ} \mathrm{C}$ for 25 and $120^{\circ} \mathrm{C}$, and the voltage signal also grew from 6.02 to $10.83 \mathrm{mV}$ for the micro-THS with 40 mass $\%$ Pt/alumina ceramic catalyst of Fig. 6 (a). However, when the 40 mass $\% \mathrm{Pt} /$ alumina ceramic catalyst was prepared using old method without ball-mill technique in Fig. 6(b), $\Delta V_{\mathrm{S}}$ values greatly depended on the operating temperature and unstably response was shown because of ununiformity of catalyst reaction from the catalyst thickness, especially, at the low operating temperature . These results show that hydrogen sensing properties of the micro-THS depended on the preparation of the catalyst, and the microTHS with the catalyst prepared using ball-mill technique had a stably response. Therefore, we focused on the catalyst powder prepared using ball-mill technique, and the hydrogen sensing properties of the micro-THS with $\mathrm{Pt} /$ alumina ceramics 

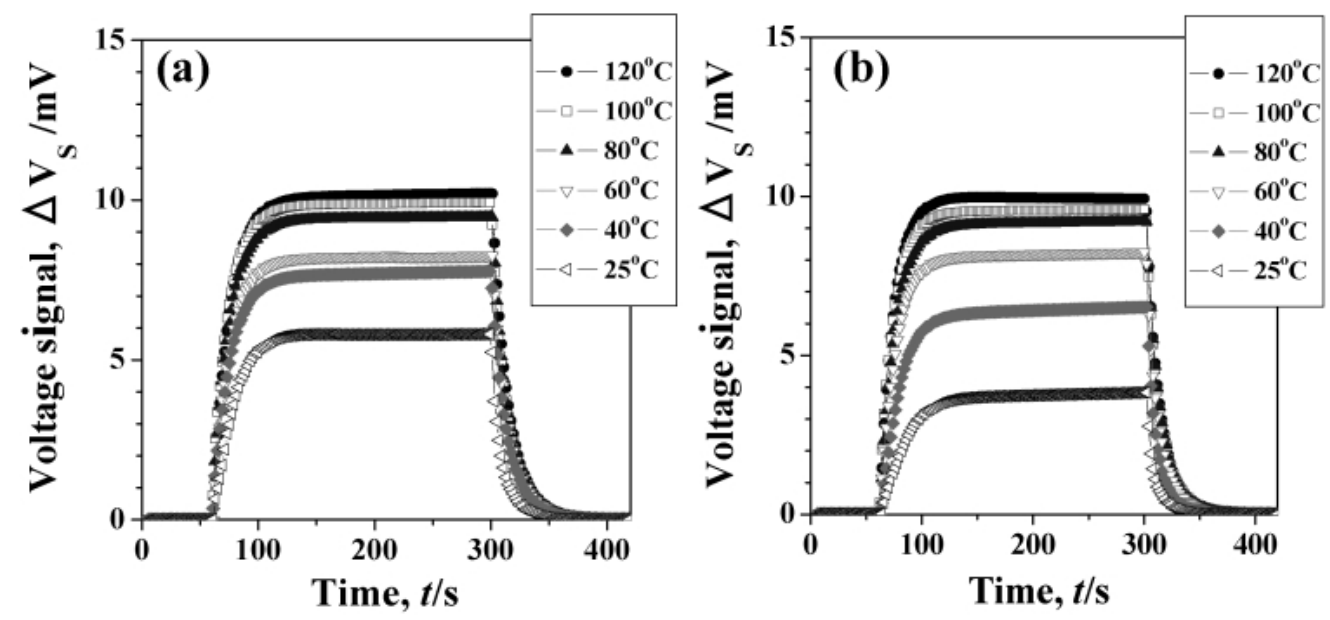

Fig. 6. Hydrogen sensing properties of micro-thermoelectric hydrogen sensors with 40 mass\% $\mathrm{Pt} /$ alumina ceramic catalysts at operating temperature of 25 to $100^{\circ} \mathrm{C}$ for $1 \%$ hydrogen in air. The starting catalyst powder of (a) was prepared using ball-mill technique, and (b) was prepared using old method without ball-mill technique.

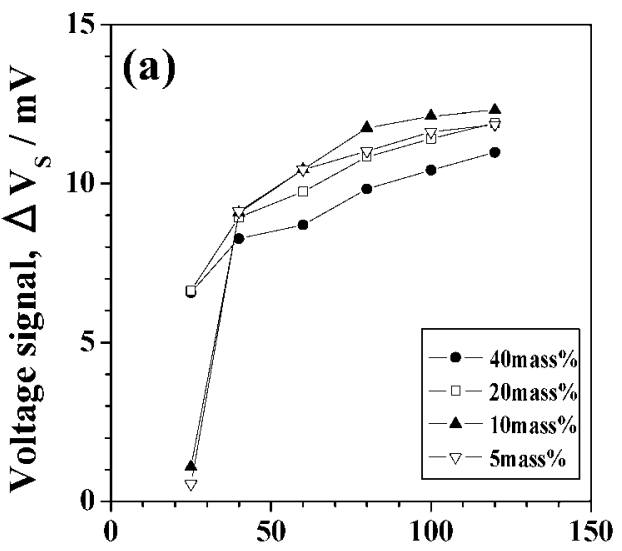

Operating temperature $/{ }^{\circ} \mathrm{C}$

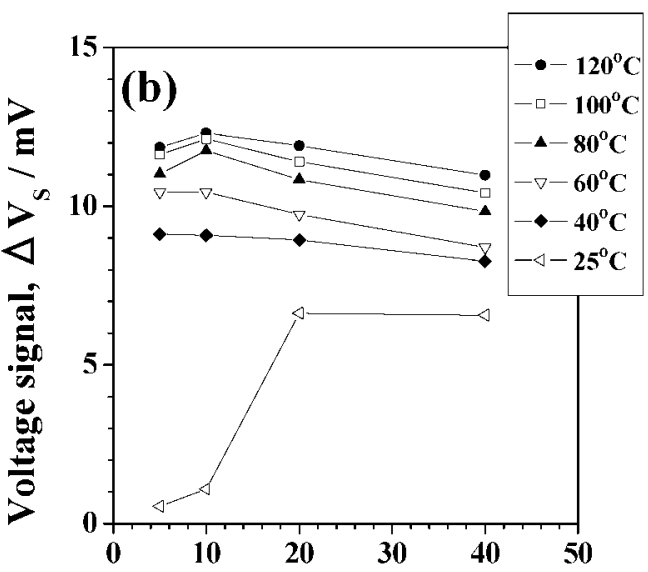

Pt content in catalyst powder / mass \%

Fig. 7. Dependences of operating temperature and platinum metal content in catalyst powder using ball-mill technique for hydrogen sensing properties of micro-thermoelectric hydrogen sensors with 5 to 40 mass\% $\mathrm{Pt} /$ alumina ceramic catalysts for $1 \%$ hydrogen in air.

catalysts which include various platinum metal contents was investigated.

Figure 7 shows the hydrogen sensing properties of the micro-THS with Pt/alumina ceramic catalyst at various operating temperatures and platinum metal content in catalyst powder for $1 \%$ hydrogen in air. The $\Delta V_{\mathrm{S}}$ at the room temperature was decreased rapidly for the micro-THS with little amount of platinum metal less than 10 mass\% in catalyst powder. However, the micro-THS with 10 mass\% $\%$ Pt/alumina ceramic catalyst showed the higher $\Delta V_{\mathrm{S}}$ value at the temperature over $80^{\circ} \mathrm{C}$ than those of other platinum metal content in catalyst powder. This indicates that the amount of platinum metal in ceramic catalyst is necessary for hydrogen-oxidized reaction involving in the $\mathrm{Pt} /$ alumina ceramic catalyst at the low operating temperature, and there is the best amount of platinum metal in catalyst powder for the operating temperature. This might be due to the effect of the agglomeration of platinum metal in the catalyst powder. However, the hydrogen-oxidized reaction at $\mathrm{Pt} /$ alumina ceramic catalyst was affected by humidity in atmosphere for the low operating temperature under $100^{\circ} \mathrm{C}$, resulting in poor $\Delta V_{\mathrm{S}}$ values. ${ }^{15)}$ There- fore, the better operating temperature for the micro-THS with $\mathrm{Pt} /$ alumina ceramic catalyst was over $100^{\circ} \mathrm{C}$ to exhaust water vapor than other operating temperatures. We chose 100 ${ }^{\circ} \mathrm{C}$ as normal operating temperature for the micro-THS with $\mathrm{Pt} /$ alumina ceramic catalyst in the view point of the low power consumption, and the sensing property was hardly changed at over $100^{\circ} \mathrm{C}$ as shown in Fig. 7 .

In our previous research, we reported the relationship between catalyst composition and catalyst activity for hydrogen gas on the silicon substrate. ${ }^{10)}$ As a result, the 40 mass $\%$ $\mathrm{Pt} /$ alumina ceramic catalyst on the silicon substrate had higher catalyst activity than that of other catalyst compositions. Therefore, the hydrogen sensing property of the sensor was investigated only catalyst composition of 40 mass\% $\% \mathrm{Pt} /$ alumina. In this study, we focused on the investigation of the hydrogen sensing property of the sensor with various catalyst compositions and predominance of the ball-mill technique for preparation of catalyst powder totally. As a result, a good catalyst performance was not demonstrated because the platinum metal was agglomerated on alumina particle surface for 40 mass \% Pt/alumina ceramic catalyst as shown in Fig. 4 (a). 
Table 1. Hydrogen Sensing Properties of the Micro-THS with Pt/Alumina Ceramic Catalysts, the Starting Catalyst Powder was Prepared using Ball-Mill Technique, at Operating Temperature of 100 and $25^{\circ} \mathrm{C}$ for $1 \%$ Hydrogen in Air

\begin{tabular}{|c|c|c|c|c|c|}
\hline Catalyst composition & $\begin{array}{l}\text { Operating temperature } \\
\qquad /{ }^{\circ} \mathrm{C}\end{array}$ & $\begin{array}{c}\text { Voltage signal } \\
\wedge V_{\mathrm{S}} / \mathrm{mV}\end{array}$ & $\begin{array}{c}\text { Catalyst activity } \\
\qquad \mathrm{T}_{\mathrm{A}} /{ }^{\prime \prime} \mathrm{C} \\
\end{array}$ & $\begin{array}{c}\text { Temperature difference } \\
\qquad \boldsymbol{\wedge \mathbf { T } _ { \mathrm { A } - \mathrm { B } }} /{ }^{\circ} \mathrm{C}\end{array}$ & $\begin{array}{c}\text { Apparent Seebeck coefficient } \\
\qquad \alpha / \mathrm{mV} \cdot \mathrm{K}^{-1}\end{array}$ \\
\hline \multirow{2}{*}{40 mass\% $\mathrm{Pt}$ /alumina } & 100 & 10.52 & 49.50 & 48.21 & 0.22 \\
\hline & 25 & 6.02 & 22.34 & 21.84 & 0.28 \\
\hline \multirow{2}{*}{20 mass \%Pt/alumina } & 100 & 11.41 & 47.97 & 44.84 & 0.25 \\
\hline & 25 & 6.63 & 21.90 & 21.54 & 0.31 \\
\hline \multirow{2}{*}{10 mass $\%$ Pt/alumina } & 100 & 12.12 & 40.51 & 40.30 & 0.30 \\
\hline & 25 & 1.09 & 1.35 & 1.33 & 0.82 \\
\hline \multirow{2}{*}{5 mass \% Pt/alumina } & 100 & 11.63 & 34.49 & 34.76 & 0.33 \\
\hline & 25 & 0.55 & 0.86 & 0.77 & 0.71 \\
\hline
\end{tabular}

However, platinum metal could be loaded on alumina particle surface with high dispersion using ball-mill technique for 10 mass\% Pt/alumina ceramic catalyst as shown in Fig. 4(b). This was a reason why the micro-THS with 10 mass\% Pt/alumina ceramic catalyst had higher sensitivity than that of other catalyst composition in this work at high operating temperature of $100^{\circ} \mathrm{C}$.

The sensing properties of the micro-THS with $\mathrm{Pt} /$ alumina ceramic catalysts at operating temperatures of 100 and $25^{\circ} \mathrm{C}$ for 1\% hydrogen in air are summarized in Table 1. Apparent Seebeck coefficients, $\Delta V_{\mathrm{S}} / \Delta T_{\mathrm{A}-\mathrm{B}}$, were estimated from the values of $\Delta V_{\mathrm{S}}$ and $\Delta T_{\mathrm{A}-\mathrm{B}}$. These correspond to the Seebeck coefficients of the SiGe thermoelectric thin films on microTHS, but are in disagreement with the measured values of 0.115 and $0.101 \mathrm{mV} / \mathrm{K}$ at 100 and $25^{\circ} \mathrm{C}$, respectively. This discrepancy between the estimated values and the measured values seemed to be due to the temperature difference between the top and bottom of ceramic catalyst. The temperature was read from the top surface, but the signal was read from the bottom part directly contacts to the electrode and thermoelectric materials. This temperature differences could depended on the thickness and the dispersion of ceramic catalyst.

For effective integration of ceramic catalyst on the microTHS, it is one of most important solutions that details of characteristic of the ceramic catalyst paste is evaluated from the viewpoint of further rheological study such as a relationship between viscosity and sheer rate. The agglomeration of the platinum metal grain on alumina surface in ceramic catalyst possibly grew up by sintering in long-term use, and the performance of the micro-THS could decrease. Considering this sintering effect, the catalyst development with better dispersion without agglomeration is necessary essential for longterm stability prohibiting unwanted platinum sintering.

\section{Conclusion}

The Pt/alumina ceramic catalyst was integrated on the micro-THS. The various platinum metal contents in ceramic catalysts were milled using ball-mill technique to improve the dispersion of catalyst powder, and were deposited on the device by dispenser method using viscous paste. This paste was deposited on micro-THS using dispenser method and the effects of the ball-mill process and catalyst composition on the sensitivity, $\Delta V_{s}$, of the micro-THS for the hydrogen/air mixture gas flow were investigated. When the ceramic catalyst was prepared using ball-mill technique, the shape of ceramic catalyst became uniform layer, and agglomeration of catalyst powder could not be observed, resulting in high sensitivity of the micro-THS. The platinum metal could be loaded on alumina particle surface with high dispersion for $10 \mathrm{mass} \% \mathrm{Pt} / \mathrm{alu}$ mina ceramic catalyst, and the micro-THS with this composition of catalyst produced the larger voltage of $12.2 \mathrm{mV}$ as a signal at the operating temperature of $100^{\circ} \mathrm{C}$ for $1 \%$ hydrogen in air than that of other catalyst compositions of $5,20,40$ mass\% $\mathrm{Pt} /$ alumina.

Acknowledgment This work was supported by the New Energy and Industrial Technology Development Organization (NEDO), Japan.

\section{References}

1) Katsuki, A. and Fukui, K., Sens. Actuators B, Vol. 52, pp. 30-37 (1998).

2) Lundstrom, I., Shivaraman, S., Svensson, C. and Lundkvist, L., Appl. Phys. Lett., Vol. 26, pp. 55-57 (1975).

3) Butler, M. A., Appl. Phys. Lett., Vol. 45, pp. 1007-1009 (1984).

4) Christofides, C. and Mandelis, A., J. Appl. Phys., Vol. 68, pp. R1-R30 (1990).

5) Tajima, K., Choi, Y., Shin, W., Izu, N., Matsubara, I. and Murayama, N., Jpn. J. Appl. Phys., Vol. 44, pp. L367-L370 (2005).

6) Tajima, K., Qiu, F., Shin, W., Izu, N., Matsubara, I. and Murayama, N., Sens. Actuators B, Vol. 108, pp. 973-978 (2005).

7) Shin, W., Imai, K., Izu, N. and Murayama, N., Jpn. J. Appl. Phys., Vol. 40, pp. L1232-L1234 (2001).

8) Shin, W., Matsumiya, M., Izu, N. and Murayama, N., Sens. Actuators B, Vol. 97, pp. 344-347 (2004).

9) Tajima, K., Qiu, F., Shin, W., Sawaguchi, N., Izu, N., Matsubara, I. and Murayama, N., Jpn. J. Appl. Phys., Vol. 43, pp. 5978-5983 (2004).

10) Choi, Y., Tajima, K., Shin, W., Izu, N., Matsubara, I. and Murayama, N., Appl. Catalysis A, Vol. 287, pp. 19-24 (2005).

11) Tajima, K., Choi, Y., Shin, W., Izu, N., Matsubara, I. and Murayama, N., J. Electrochem. Soc., Vol. 153, pp. H58-H62 (2006).

12) Tajima, K., Shin, W., Itoh, T., Izu, N., Matsubara, I. and Murayama, N., J. Ceram. Soc. Japan, Vol. 113, pp. 558-561 (2005).

13) Shin, W., Choi, Y., Tajima, K., Izu, N., Matsubara, I. and Murayama, N., Sens. Actuators B, Vol. 108, pp. 455-460 (2005).

14) Williamson, G. K. and Hall, W. H., Acta Metall., Vol. 1, pp. 22-31 (1953).

15) Sawaguchi, N., Shin, K., Izu, N., Matsubara, I. and Murayama, N., Sens. Actuators B, Vol. 108, pp. 461-466 (2005). 